\title{
The Use of Zinc Oxide Nanoparticles in Eva to Obtain Food Packing Films
}

\section{Clara Teixeira de Oliveira, Jorge Pereira Chimanowsky Junior, Maria Inês Bruno Tavares}

Instituto de Macromoléculas Professora Eloisa, Universidade Federal do Rio de Janeiro, Centro de Tecnologia, Bloco J, Ilha do Fundão, CP, Rio de Janeiro, RJ, Brazil

Email: mibt@ima.ufrj.br

How to cite this paper: de Oliveira, C.T., Junior, J.P.C. and Tavares, M.I.B. (2020) The Use of Zinc Oxide Nanoparticles in Eva to Obtain Food Packing Films. Advances in Nanoparticles, 9, 59-80. https://doi.org/10.4236/anp.2020.93005

Received: July 17, 2020

Accepted: August 28, 2020

Published: August 31, 2020

Copyright $\odot 2020$ by author(s) and Scientific Research Publishing Inc. This work is licensed under the Creative Commons Attribution International License (CC BY 4.0).

http://creativecommons.org/licenses/by/4.0/

\section{(c) (i) Open Access}

\begin{abstract}
The increasing demand for new packages with increased shelf life properties has stimulated the increase of research in the active packaging sector. The use of antimicrobial agents requires an in-depth study of their properties to avoid loss of efficiency of the polymer processing. In this context, the objective of this work was to evaluate the preparation of an $18 \%$ ethylene vinyl acetate copolymer (EVA) nanocomposite and zinc oxide $(\mathrm{ZnO})$ as microbicidal nanoparticle, prepared in a monosulfon extruder. The nanoparticle was modified with octadecylamine and EVA 18 nanocomposite films were prepared and compared to the systems containing modified nanoparticle. These new materials were characterized by thermogravimetric analysis (TGA), Differential Scanning Calorimetry (DSC), X-Ray Diffraction (XRD), Dynamic Mechanical Analysis (DMA), Time Domain Nuclear Magnetic Resonance (NMR) to investigate the effect of zinc oxide nanoparticles on thermal properties, EVA crystallinity and antimicrobial effect. The TGA showed a tendency of increase of the thermal stability in different proportions of ZnO. DSC results did not show significant changes in thermal parameters. The XRD analysis showed an increase in the degree of crystallinity of the nanocomposites in relation to the EVA matrix and change in the crystallinity with the increase of $\mathrm{ZnO}$ percentages. DMA analysis indicates change in structural organization through the variation of storage modulus, loss, and tan delta. Time domain NMR data corroborate with XRD data through the change in molecular mobility.
\end{abstract}

\section{Keywords}

Food Packaging, Ethylene Vinyl Acetate Copolymer, Antimicrobial, ZnO

\section{Introduction}

Knowing that the requirements for food packaging have changed over the years 
with a growing demand for packaging materials that are stronger, lighter and have certain functional properties, food needs adequate packaging to maintain quality and freshness during transportation and storage, as well as to prolong the shelf life by controlling humidity, gases and certain volatile components, such as flavorings [1].

Traditionally, the food packaging industry develops materials for preserving and protecting food from environmental factors starting from production site to the point of consumption. These traditional systems are reaching their limits regarding extending the shelf life of packaged foods. To provide this shelf life extension and improve quality and integrity of packaged foods, innovative concepts of active packaging are being developed [2] [3].

The purpose of the active packaging is to extend shelf life by applying various strategies, such as: oxygen removal, moisture control and addition of other active materials in its composition for food protection. These developments in active packaging have led to advances in many industries, including late oxidation in sport supplements, controlled rate of respiration in vegetables and antimicrobial action [4].

Antimicrobial packaging is a form of active packaging in which the microbicidal agent acts to reduce, inhibit or retard the growth of microorganisms present in the packaged food or in the packaging material itself. Incorporation of antimicrobial agents can be done via direct coating in packaging or processed along with polymer matrix [5] [6].

To develop antimicrobial packaging films, microbicidal nanoparticles are incorporated into the polymer matrix through two possible methods: solution or fusion. Zinc oxide $(\mathrm{ZnO})$ is an inorganic compound widely used in everyday applications and is a material generally recognized as safe by the Food and Drug Administration (21CFR182.8991) and has already shown antimicrobial activity against foodborne pathogens [6]-[28].

Ethylene-co-vinyl acetate (EVA) is a copolymer with wide industrial applications due to its stable physicochemical properties, which make it distinct from other copolymers. This copolymer has low gas permeability and, therefore, it is used in the packaging industry in the form of film [29] [30].

Due to the increasing demand for research in the field of bactericidal and fungicidal for packaging, this work aims the detailed study of polymer nanocomposites containing antimicrobial agents, as is the case of zinc oxide and its well-known antimicrobial property. The proposal of the present work addresses the method of processing, which includes compatibility with the polymer matrix, types of pathogens affected and mechanical properties of the new packaging.

\section{Materials}

Poly(ethylene co vinyl acetate) (EVA) from Polietileno União (Brazil), EVA UE-1825 with mass content of $18 \mathrm{wt} \%$ vinyl acetate

Nanostructured zinc oxide from Sigma Aldrich - Brazil with $15-25 \mathrm{~m}^{2} / \mathrm{g}$ surface area. 


\section{Experimental}

\subsection{Zinc Oxide Modification}

Experimental procedure started by weighting $0.8 \mathrm{mg}$ of stearic acid along with $200 \mathrm{ml}$ butanol, then sonicating for 5 minutes at max power. Zinc oxide was added to butanol solution of stearic acid, and then magnetic stirring was applied for $24 \mathrm{~h}$.

Subsequently, the solution was split and poured into 5 falcon tubes and centrifuged at $3500 \mathrm{rpm}$ for 5 minutes. The acid supernatant was removed, and ethyl acetate was added to complete the tubes. All tubes were sonicated for 20 minutes; then the tubes were centrifuged under the same conditions 3 times. The ethyl acetate was withdrawn from the tubes and solid was dried for $24 \mathrm{~h}$.

The oxide was transferred to an erlenmeyer flask containing $100 \mathrm{~mL}$ ethanol, then the solution was added to another solution containing $100 \mathrm{~mL}$ of ethanol and $1.2 \mathrm{~g}$ of octadecylamine. The erlenmeyer was kept under stirring for $1 \mathrm{~h}$, then the solution was centrifuged under the same previously mentioned conditions and there were 5 washes with ethyl acetate, then the solution was withdrawn and divided into two falcon tubes again. After the last wash, the ethyl acetate was withdrawn and the modified $\mathrm{ZnO}$ dried in the falcon tube for at least 24 hours.

After the modification of the zinc oxide, three methods of characterization were used: Thermogravimetric analysis (TGA), X-ray diffraction (XRD) and Fourier Transform Infrared Spectroscopy (FTIR)

\subsection{Films Fabrication}

The polymer matrix used for antimicrobial packaging formulation was the ethylene-vinyl acetate copolymer with $18 \%$ acetate (EVA 18), purchased as pellet. Zinc oxide was chosen as the antimicrobial agent. Nanocomposites of EVA 18 were produced through melt mixing with $0.25 \% \mathrm{ZnO}$; $0.5 \% \mathrm{ZnO} ; 0.75 \% \mathrm{ZnO}$ and $1 \% \mathrm{ZnO}$, being denominated E18-0.25ZnO, E18-0.5ZnO, E18-0.75ZnO and E18-1ZnO, respectively.

The EVA18 copolymer was frozen in Ultrafreezer at $-90^{\circ} \mathrm{C}$ for grinding to avoid possible melting of the copolymer with the heat generated by the mill.

The frozen EVA18 pellets were milled using a knife mill. This step guarantees the increase of the contact surface of EVA, which facilitates the homogeneous diffusion of the heat of the extruder during melting and allowing greater contact with the nanoparticle.

The obtained EVA18 granules were oven dried at $40^{\circ} \mathrm{C}$ for 24 hours for complete removal of moisture from the material. This drying was important to avoid bubbles during extrusion, generating a more homogeneous material during processing.

After drying, the material was processed in a single-screw extruder from AX Plastics, $14 \mathrm{~mm}$ diameter, L/D: 22, equipped with matrix for flat films. Extrusion conditions include temperatures of $140^{\circ} \mathrm{C}, 150^{\circ} \mathrm{C}$ and $180^{\circ} \mathrm{C}$ in zones 1,2 and 3 , 
respectively, with torque $38 \mathrm{Nm}$ and residence time of 1 minute. The extruder was coupled to a Haake Fisons roller puller with a speed of $60 \mathrm{rpm}$.

Rotation speed of screw was modified following the variation of zinc oxide amount incorporated in the nanocomposites. Increasing the amount of oxide increased the viscosity of the material, increasing its resistance to flow; therefore, the rpm of the thread was increased during extrusion. 60, 70, 80, 90 and $90 \mathrm{rpm}$ were used for the films containing $0 \% ; 0.25 \% ; 0.5 \% ; 0.75 \%$ and $1 \% \mathrm{ZnO}$, respectively. The sample was cooled and solidified on the roll, which permitted to obtain the film form.

\subsection{Characterization}

The obtained films were characterized by the techniques of: Fourier Transform Infrared Spectroscopy (FTIR), Thermogravimetric Analysis (TGA), X-ray Diffraction (XDR), Differential Scanning Calorimetry (DSC), Time Domain Nuclear Magnetic Resonance (TD-NMR) and Dynamic Mechanical Analysis (DMA). Using the following conditions:

FITR: The Perkin Elmer Spectrum FTIR Version: 10.4.2 - Model: Frontier FT-IR/FIR United Kingdom spectrometer, was stetted the frequency range from 4000 to $400 \mathrm{~cm}^{-1}$, using ATR mode.

TGA: Thermogravimetric Analyzer TGA Q500 V6.7/Build Instrument 203/Module TGA was used to the analyzed the samples in $\mathrm{N}_{2}$ atmosphere; temperature range from $30^{\circ} \mathrm{C}$ to $700^{\circ} \mathrm{C}$; heating rate of $10^{\circ} \mathrm{C} / \mathrm{min}$. The error is $\pm 2^{\circ} \mathrm{C}$.

XDR: The samples were analyzed in X-ray diffractometer Rigaku Miniflex, Japan, using angle $2 \theta$ between $2^{\circ}$ and $60^{\circ}$; scan rate of $0.5^{\circ} / \mathrm{min}$; wavelength $\lambda=$ $0.154 \mathrm{~nm}$; X-ray generation source Copper.

DSC: Differential scanning calorimeter, Rigaku, model TAS 100 with accessory, USA Thermoflex TG 8110, three heating were done in the samples. First heating curve from $-50^{\circ} \mathrm{C}$ to $220^{\circ} \mathrm{C}$, at $5^{\circ} \mathrm{C} / \mathrm{min}$, applying $1 \mathrm{~min}$ isotherm at $200^{\circ} \mathrm{C}$; in the second cycle the sample was cooled down to $-50^{\circ} \mathrm{C}$; the third cycle was performed under the same conditions as the first cycle. The error is $\pm 2{ }^{\circ} \mathrm{C}$.

TD-NMR: Were performed by determining the longitudinal relaxation time of the hydrogen nucleus $\left(\mathrm{T}_{1} \mathrm{H}\right)$. The samples were placed in the probe in an $18 \mathrm{~mm}$ tube. The pulse sequence used was inversion-recovery; with the described conditions $90^{\circ}$ pulse; temperature $30^{\circ} \mathrm{C} \pm 2{ }^{\circ} \mathrm{C} ;{ }^{1} \mathrm{H}$ probe with frequency of $23 \mathrm{MHz}$; the range of time between pulses varied from 0.01 to $10,000 \mathrm{~ms}$ using a list of points from $100-5,000,000 \mu$ s. The error of the measurement is around $2 \%$.

DMA: Dynamic mechanical analyzer (Q-800, TA Scientific) was employed for performing dynamic mechanical films at a fixed frequency of $1 \mathrm{~Hz}$ and oscillation amplitude of $0.15 \mathrm{~mm}$. The measurements were carried out by heating from $30^{\circ} \mathrm{C}$ to $170^{\circ} \mathrm{C}$ under nitrogen atmosphere at a heating rate of $5^{\circ} \mathrm{C} / \mathrm{min}$.

\section{Results and Discussion}

The EVA/ZnO systems were obtained in proportions of $0.25 \% ; 0.5 \%, 0.75 \%$ and 
$1 \% \mathrm{ZnO}$ while EVA/ZnOmod systems had $0.25 \%$ and $0.5 \%$ modified nanoparticle. The films were obtained continuously and showed uniformity and absence of bubbles, imperfections, or faults (Figure 1). The increase of oxide proportions in the films caused an opacity in the materials, which could come from the modification in polymer structural organization and/or the variation of oxide dispersion in the polymer matrix [31] [32].

The efficiency of films processing was verified through TGA, DSC and XRD analyzes, where the samples obtained with the same percentage of $\mathrm{ZnO}$ were analyzed in different parts of the film. The different samples of each roll presented consistent results, which evidences proper film processing.

\subsection{Fourier Transform Infrared Spectroscopy}

Zinc oxide was analyzed by FTIR to confirm the success of its modification process. FTIR spectra of $\mathrm{ZnO}$ showed a few absorption peaks (Figure 2), corresponding

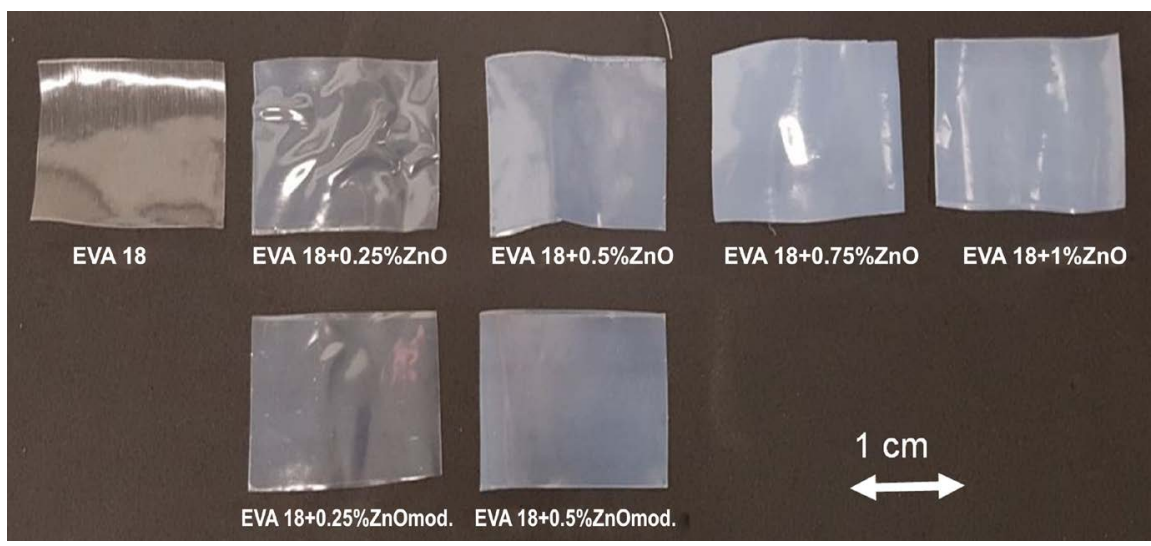

Figure 1. EVA/ZnO films obtained by melting.

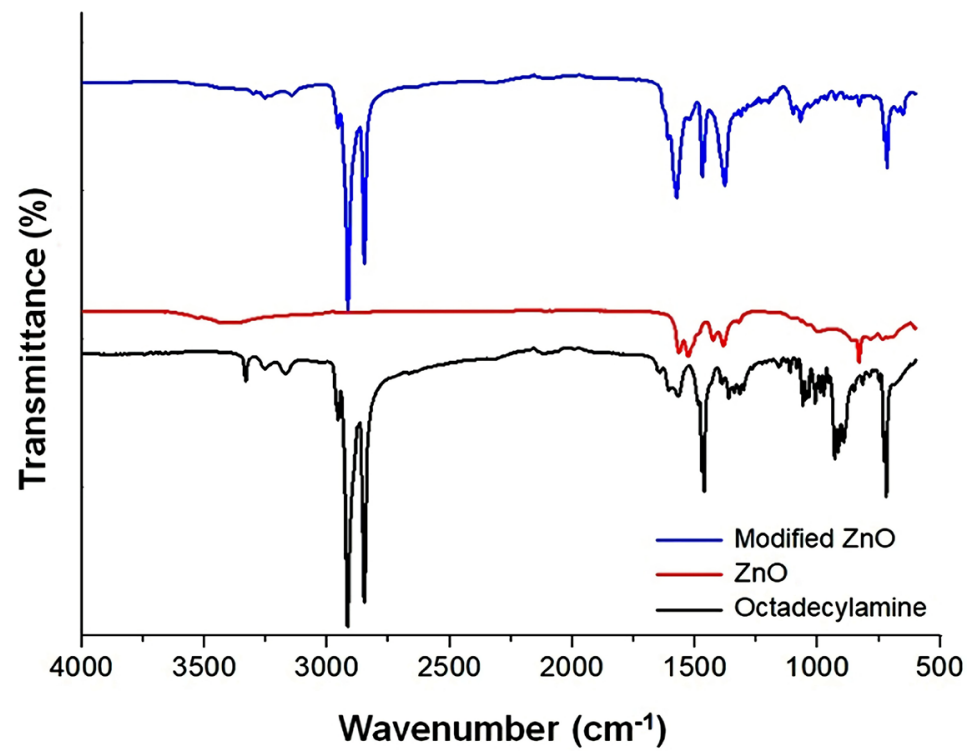

Figure 2. Infrared spectra of pure oxide $(\mathrm{ZnO})$, organic modifier and modified nanoparticle (modified $\mathrm{ZnO}$ ). 
to the carboxylate impurities. The peaks observed at 1630 and $1384 \mathrm{~cm}^{-1}$ are due to the asymmetric and symmetrical stretching of the zinc carboxylate, respectively. The carboxylate probably comes from plasma species containing reactive carbon during the synthesis [33].

The chemical modification was confirmed by the presence of the octadecylamine peaks relative to the $-\mathrm{CH}_{2}$ bond at wavelength 2918,2848 and $720 \mathrm{~cm}^{-1}$, and the band at $1466 \mathrm{~cm}^{-1}$ related to the stretching of the C-N amide bond [34].

FTIR analysis of the obtained EVA/ZnO systems showed no change in the characteristic peaks of the EVA copolymer after zinc incorporation (Figure 3), indicating only a possible physical interaction between the oxide and the copolymer [35] [36].

Through the carbonyl band it can be verified degradation reactions of polymer matrix throughout processing [37]. As there is no new carbonyl band pertaining to EVA degradation, increase of intensity and nor displacement of the EVA acetate band at $1744 \mathrm{~cm}^{-1}$, the analysis indicates absence of copolymer degradation during processing.

Regarding to pure EVA, the analysis of the modified nanoparticle-containing systems (Figure 4) also showed no change in the peak intensities for the carbonyl, indicating that the nanoparticle modification did not accelerate the degradation process and indicates the formation only of a physical interaction in the systems.

\subsection{X-Rays Diffraction}

Figure 5 shows that the EVA presents two characteristic peaks centered at $21^{\circ}$ and $23^{\circ}$, corresponding to planes 110 and 200 of the orthorhombic structure of

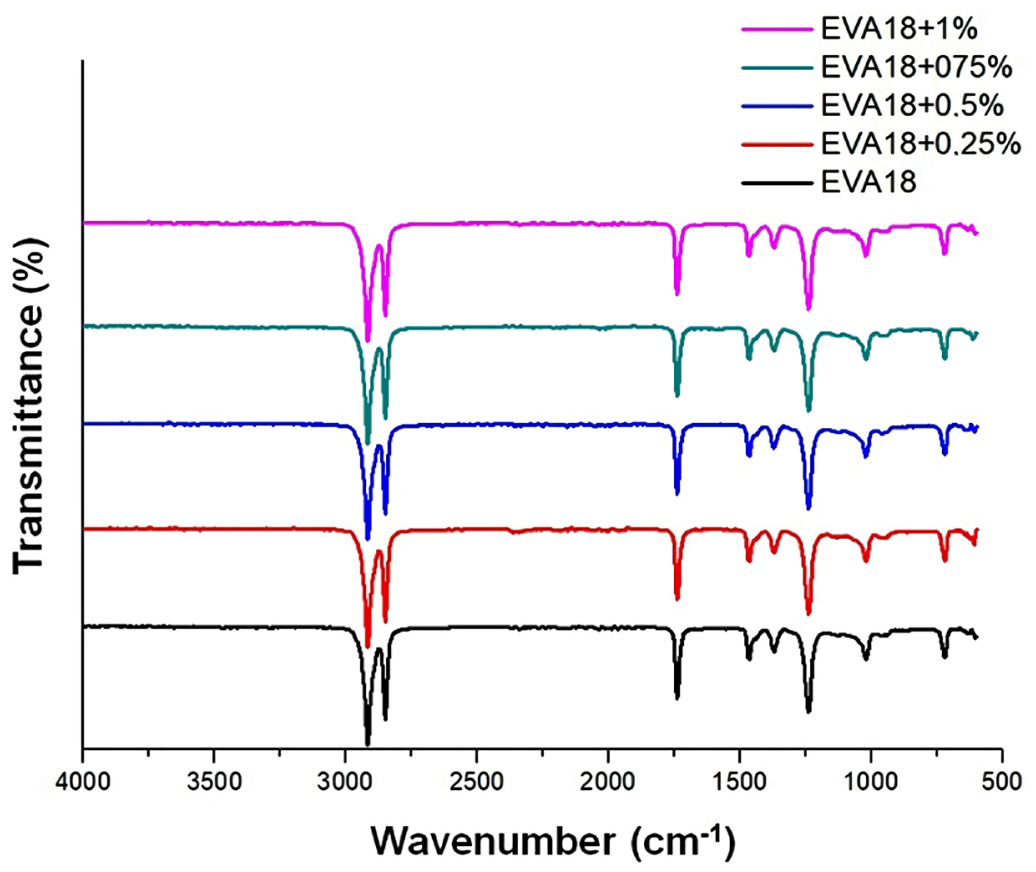

Figure 3. Infrared spectra of the EVA and $\mathrm{ZnO}$ systems in different oxide ratios. 


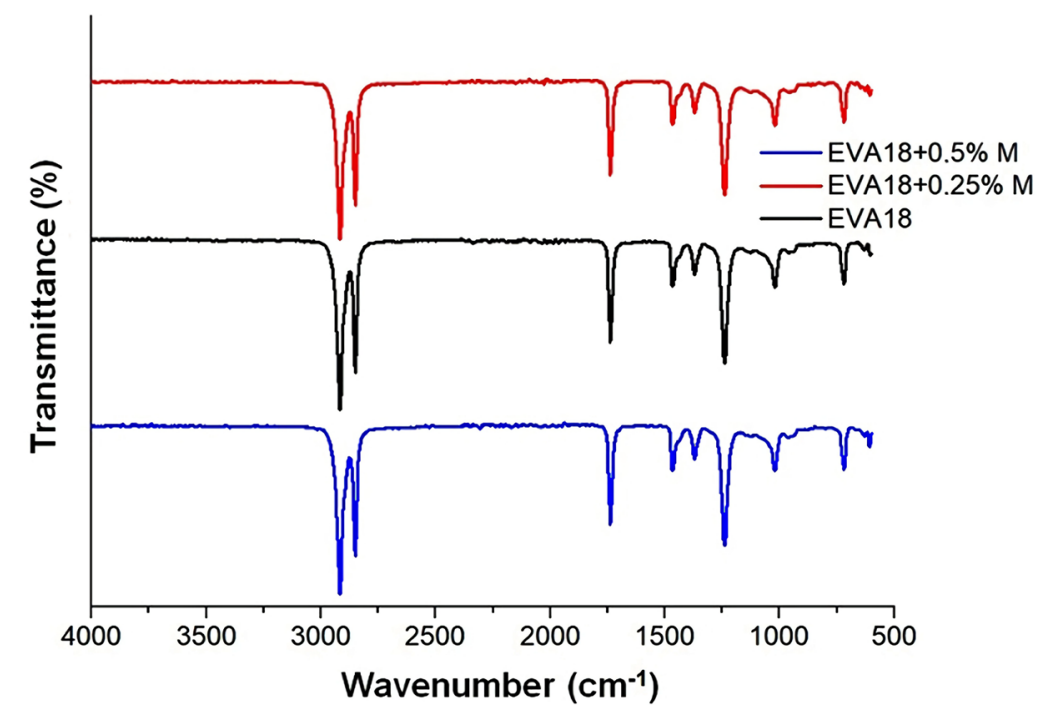

Figure 4. Infrared spectra of the EVA/ZnOmod systems. In $0.25 \%$ and $0.5 \%$ modified zinc oxide.

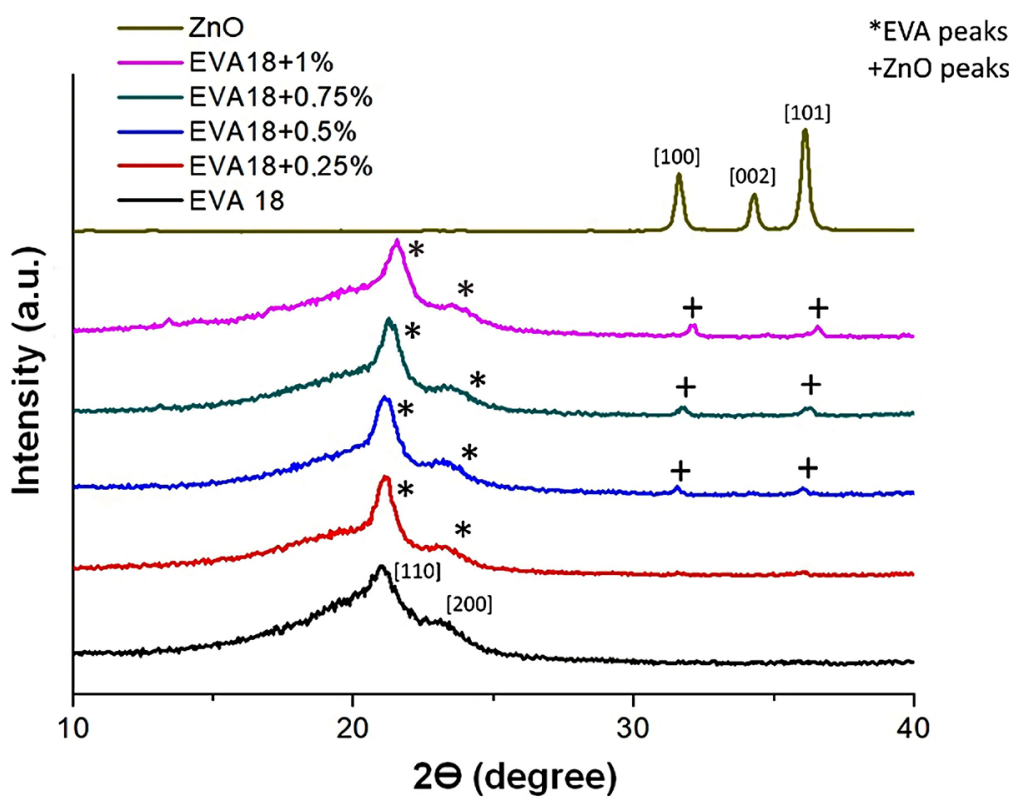

Figure 5. Diffractogram corresponding to different EVA/ZnO systems in various proportions of zinc oxide.

EVA [38]. Vinyl acetate incorporation controls crystallinity degree, which is corresponding to the long ethylene segment [39] [40] [41] [42]. Thus, the broad peak of EVA is due to the $18 \%$ vinyl acetate content present in this copolymer.

The addition of zinc oxide in the EVA matrix intensifies the crystalline peak of the EVA/ZnO systems indicating that the oxide favors the organization of the system. A significant change is observed in the amorphous phase, which may indicate that the zinc oxide induces crystalline packaging of polymer chains that consequently decreases the amorphous region.

The variation of the nanoparticles content in the EVA/ZnO systems evidenced 
increased crystallization of the copolymer, as shown in Figure 5, indicating that there was greater structural organization of EVA along oxide incorporation. Moreover, oxide contents above $0.5 \%$ induced a decrease of composites organization, with the appearance of peaks related to zinc oxide. In the system containing $1 \%$ of $\mathrm{ZnO}$ it is observed a similar behavior to the pure polymer.

When evaluating the organic modifier $0.25 \% \mathrm{ZnO}$ composite (Figure 6), it is was verified the base narrowing indicating a decrease of the amorphous area with the presence of the modifier. This may be due to the better interaction of matrix-modified zinc in the amorphous area, limiting the movement of the chains and increasing the structural organization of the polymer.

In the $0.5 \%$ oxide system (Figure 7 ), there was an inversion behavior with respect to the $0.25 \%$ system, where the presence of the modifier decreased the base narrowing. The change on the EVA/ZnOmod. $0.5 \%$ system performance and the presence of oxide peaks in the diffractogram of the $0.5 \% \mathrm{EVA} / \mathrm{ZnO}$ system may indicate a border concentration, where there is variation of the matrix oxide dispersion.

\subsection{Thermogravimetric Analysis (TGA)}

EVA presents two thermal degradation stages as shown in Figure 8. The first one starts at about $300^{\circ} \mathrm{C}$ with a peak at $328^{\circ} \mathrm{C}$ and refers to the loss of acetic acid. The second degradation stage starts at $420^{\circ} \mathrm{C}$ with a peak at $447^{\circ} \mathrm{C}$, which refers to the degradation of the olefin meres ( $\mathrm{C}-\mathrm{C}$ and $\mathrm{C}-\mathrm{H}$ bonds) [38].

However, by observing the TGA profiles of Figure 8 , it can be observed that in pure EVA, a slight decline immediately occurs immediately after the acetate loss, which indicates the onset of ethylene loss. With the addition of the nanoparticles, there is a degradation stability of this portion up to $400^{\circ} \mathrm{C}$, with a tendency

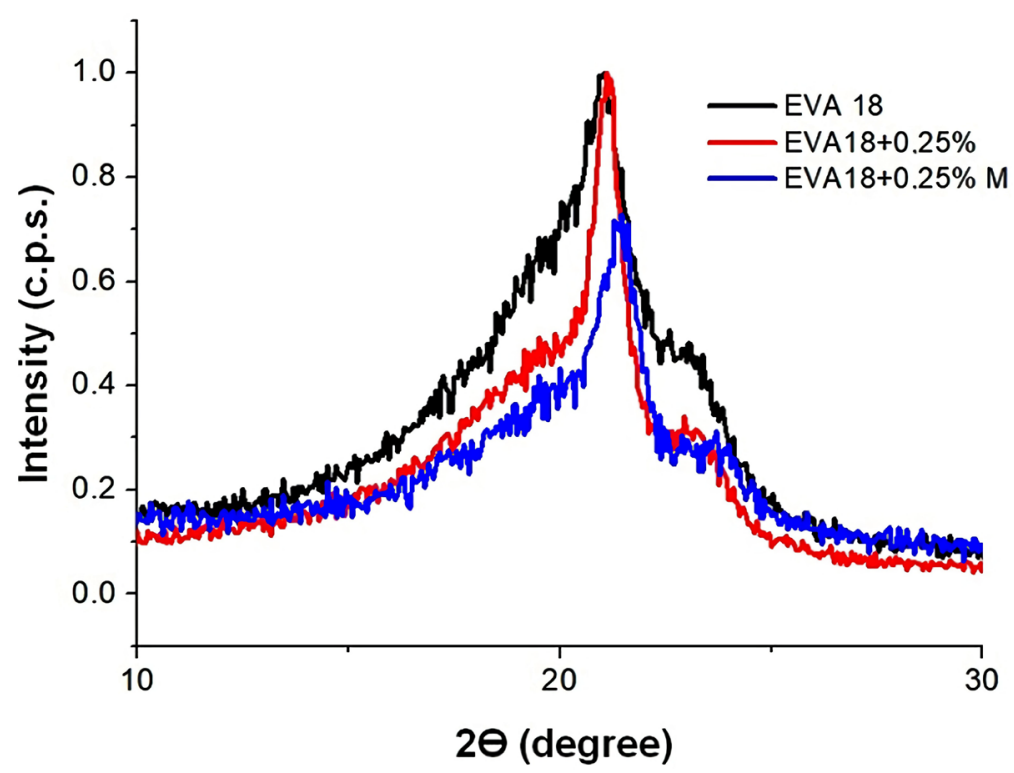

Figure 6. Diffractogram corresponding to the EVA/ZnO and EVA/ZnOmod systems containing $0.25 \% \mathrm{ZnO}$ compared to the pure copolymer. 


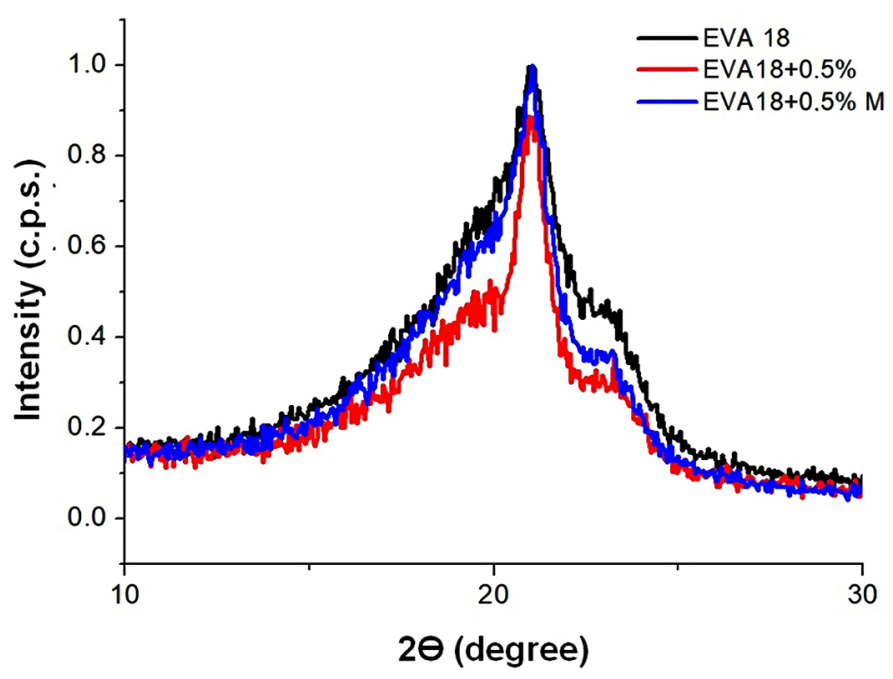

Figure 7. Diffractogram corresponding to the EVA/ZnO and EVA/ZnOmod systems containing $0.5 \% \mathrm{ZnO}$ compared to the pure copolymer.
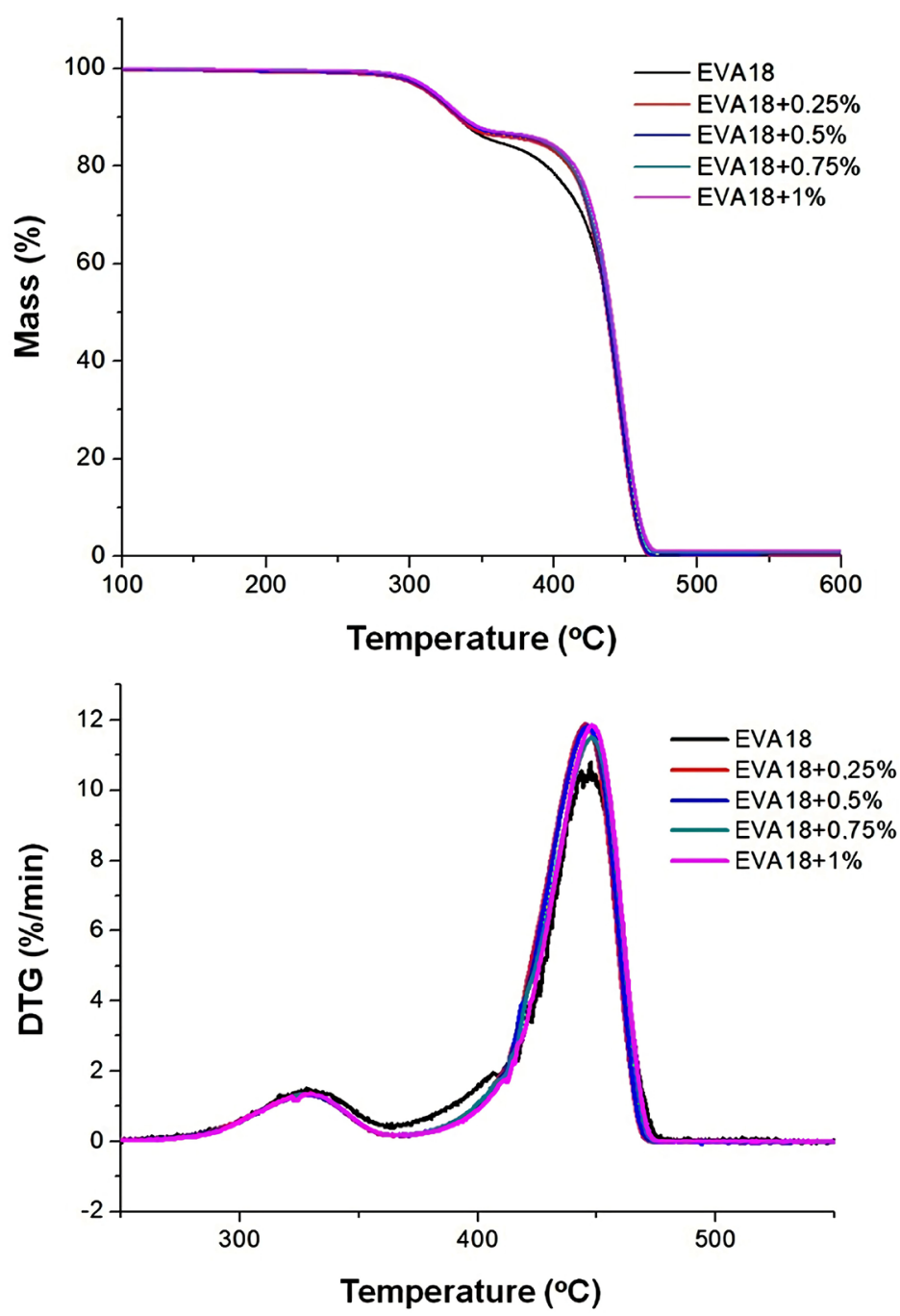

Figure 8. Thermogravimetric analysis of EVA/ZnO nanocomposites in different proportions containing derivative to show change in stability. 
for increased thermal stability. This increase in thermal stability can be attributed to the high thermal stability of $\mathrm{ZnO}$ networks and the existence of interactions between nanoparticles and polymer matrix [43].

Systems containing modified $\mathrm{ZnO}$ (Figure 9) showed the same behavior of unmodified $\mathrm{ZnO}$ systems, indicating that the modification does not alter the degradability of the material and the intermolecular interactions is only physical.

\subsection{Differential Scanning Calorimetry (DSC)}

Figure 10 presents the system's first heating curve evidencing the thermal history

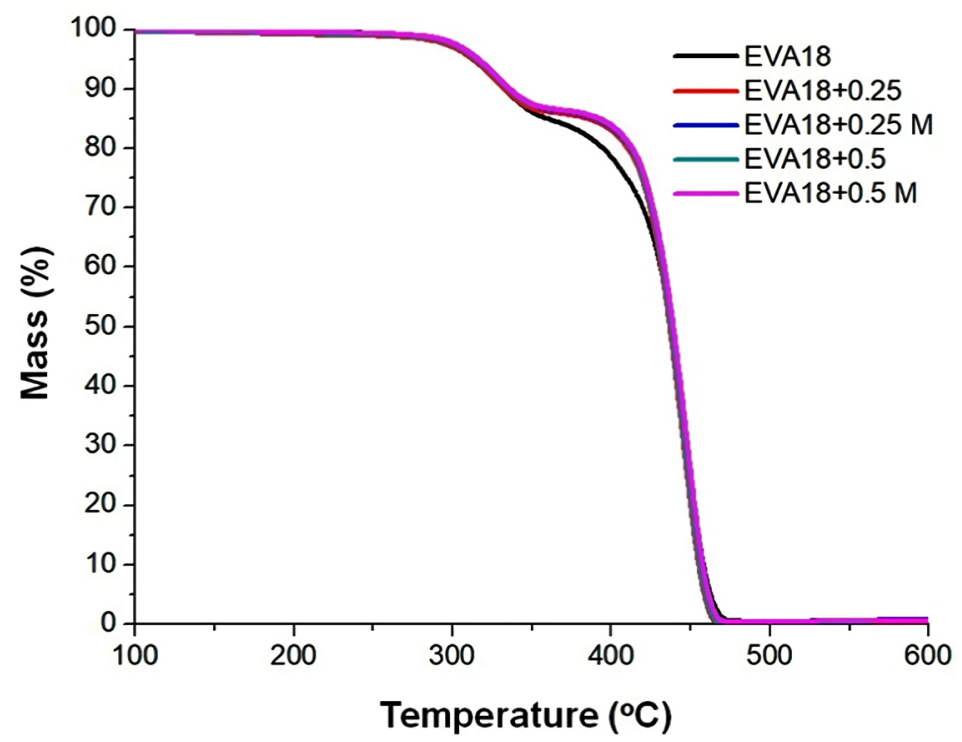

Figure 9. Thermogravimetric analysis of EVA/ZnOmod nanocomposites, containing $0.25 \%$ and $0.5 \%$ compared to EVA/ZnO systems in the same proportions and pure EVA.

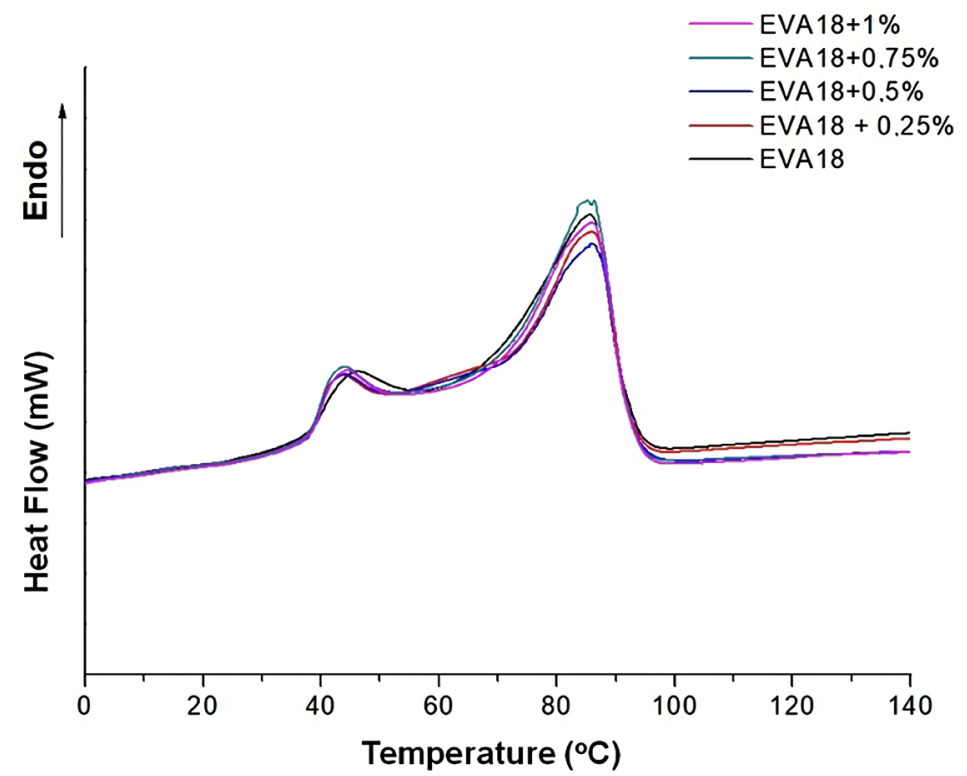

Figure 10. Differential Scanning Calorimetry analysis of the EVA/ZnO systems in different proportions referring to the 1 st heating. 
of the material. Two populations with distinct mobility were found, both in EVA 18 , and in all EVA/ZnO systems. Comparing the pure polymer with the systems obtained, it was verified that in the obtained systems, crystal melting occurs with different enthalpy variations of pure EVA, which indicates change in structural organization. The EVA/ZnO systems containing $0.75 \%$ and $1 \% \mathrm{ZnO}$ behave similarly to pure polymer.

Based on the curves obtained in Figure 11, which are relative to the cooling and 3rd heating, it can be observed that the profile of DSC curves does not change for any of the analyzed systems. This behavior indicates that the crystalline organization was not significantly altered by the presence of zinc oxide in the systems, with predominance of the oxide in the amorphous part of the matrix; this occurs because the zinc oxide size is too small and it cannot interfere in the crystalline region. This fact also confirms that the intermolecular interactions are only physical and not strong.

The parameters related to the DSC analysis (crystallization temperature $\left(T_{c}\right)$ and crystalline melting temperature $\left(T_{m}\right)$ ), obtained by third heating and cooling, were not affected by the presence of nanoparticle in the system, as shown in the Table 1 . For the calculation of the crystallinity degree of the samples, the $\Delta H_{m}$ of $100 \%$ crystalline $\mathrm{PE}=290 \mathrm{~J} / \mathrm{g}$ [44] [45] the formula used was: $X_{c}=$ $\left(\Delta H_{m} / \Delta H_{f} 100\right) \times 100 \%$.

The evaluation of the degree of crystallinity measured by DSC allowed us to verify that the technique was not very efficient for the evaluation of the $\mathrm{EVA} / \mathrm{ZnO}$ and EVA/ZnOmod systems. This occurs since the crystallinity degree is obtained by relative measurement, through the variation of the melting enthalpy of the material. The XRD technique, on the other hand, had a greater sensitivity to verify the crystallinity of the systems, since it is an absolute technique.

\subsection{Dynamic-Mechanical Analysis (DMA)}

The dynamic-mechanical analysis allows the separation of the elastic and viscous contribution in viscoelastic materials, as a function of both temperature and time. Regarding the pure polymer, the storage modulus decreased with the insertion

Table 1. Thermal parameters obtained by DSC analysis.

\begin{tabular}{|c|c|c|c|c|c|}
\hline Sample & $T_{c}\left({ }^{\circ} \mathrm{C}\right)$ & $\begin{array}{c}T_{m} 1 \text { st heat. } \\
\left({ }^{\circ} \mathrm{C}\right)\end{array}$ & $\begin{array}{c}T_{m} 3 \text { rd heat } \\
\left({ }^{\circ} \mathrm{C}\right)\end{array}$ & $\Delta H_{m}(\mathrm{~J} / \mathrm{g})$ & $\begin{array}{c}\text { Degree of } \\
\text { crystallinity (\%) }\end{array}$ \\
\hline EVA 18 & 72 & $46 / 86$ & 86 & 64 & 22 \\
\hline $\mathrm{EVA} 18+0.25 \% \mathrm{ZnO}$ & 72 & $43 / 86$ & 87 & 72 & 25 \\
\hline EVA18 + 0.25\%ZnOmod. & 72 & $43 / 86$ & 87 & 63 & 22 \\
\hline $\mathrm{EVA} 18+0.5 \% \mathrm{ZnO}$ & 73 & $43 / 86$ & 87 & 78 & 27 \\
\hline EVA18 + 0.5\%ZnOmod. & 72 & $44 / 86$ & 87 & 60 & 21 \\
\hline $\mathrm{EVA} 18+0.75 \% \mathrm{ZnO}$ & 73 & $45 / 86$ & 87 & 64 & 22 \\
\hline $\mathrm{EVA} 18+1 \% \mathrm{ZnO}$ & 73 & $44 / 86$ & 87 & 70 & 25 \\
\hline
\end{tabular}



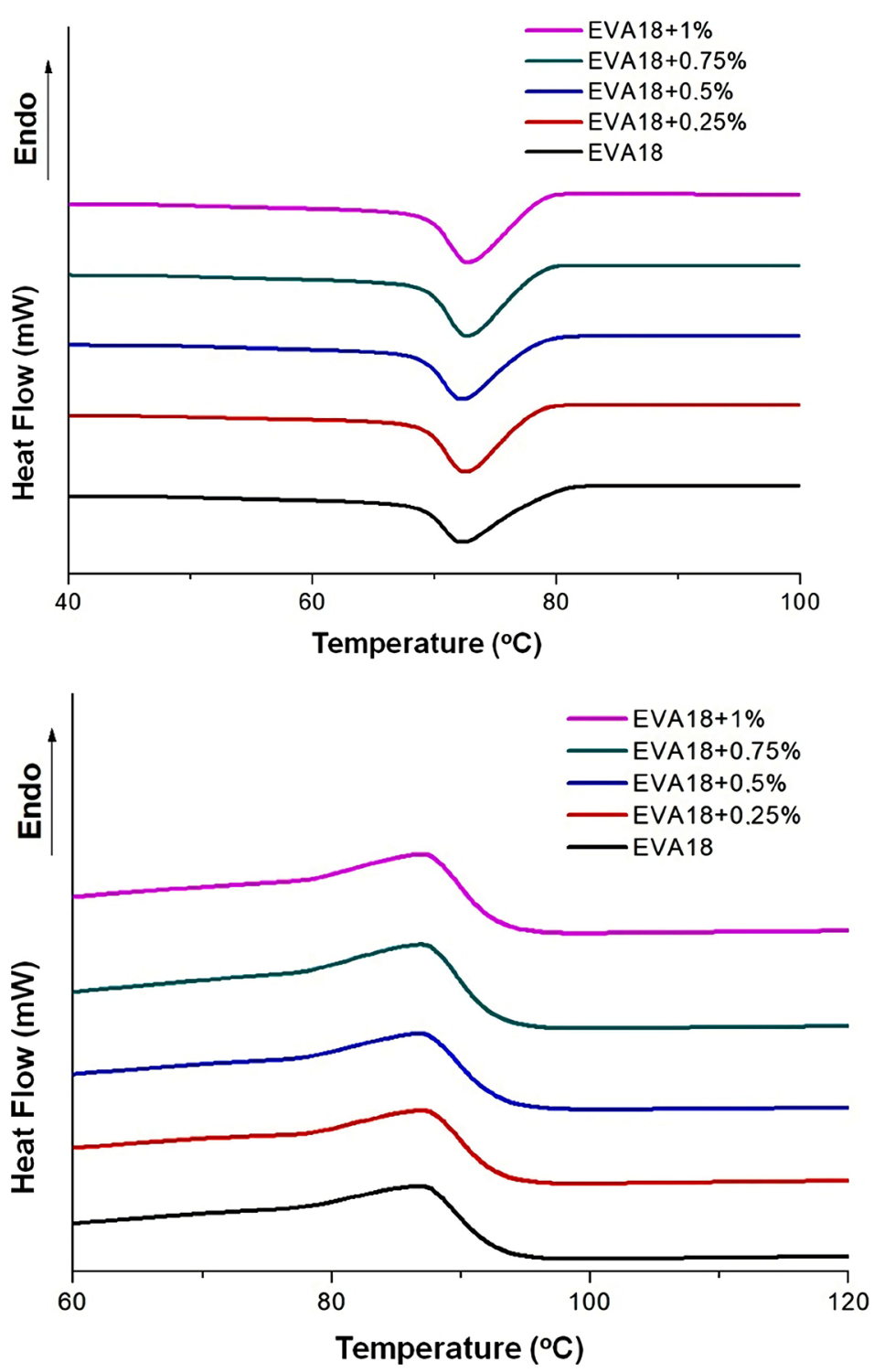

Figure 11. Scan Differential Calorimetry analysis of the EVA/ZnO systems in different proportions, relative to the cooling (left) and third heating (right).

of nanoparticle into the matrix (Figure 12). This indicates that the nanoparticle/matrix interaction also promoted a modification in the structural organization of EVA, not only due to the processing, but also due to the presence of $\mathrm{ZnO}$ in the polymer matrix. The presence of nanoparticle in the polymer matrix modified the chain motility, altering the mechanical relaxation and making the material phase response difficult.

Figure 13 shows that increasing the $\mathrm{ZnO}$ concentrations to $0.75 \%$ and $1 \%$ further decreases the storage modulus. Such evidence indicates little adhesiveness of the nanoparticle in the matrix, further decreasing the response in phase. This process was probably caused by the change in dispersion and distribution of the nanoparticle, which was also observing in the XRD analysis by the appearance of $\mathrm{ZnO}$, indicating an increase in the amorphous contribution. For 


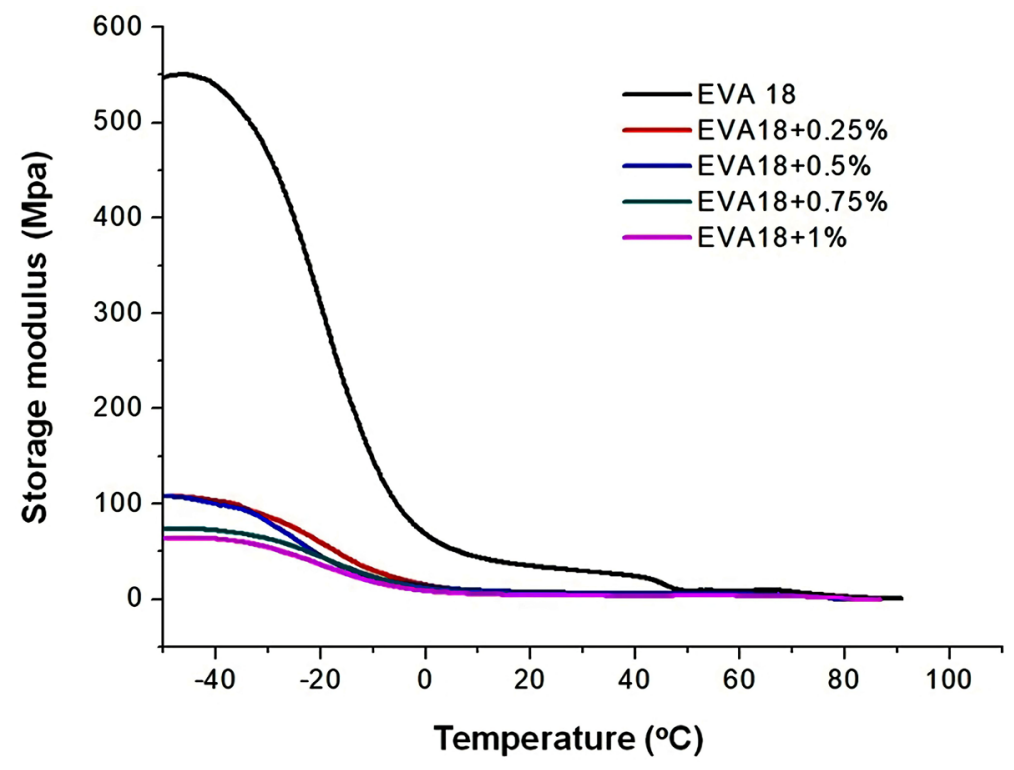

Figure 12. Storage module of EVA/ZnO systems in different proportions of $\mathrm{ZnO}$.

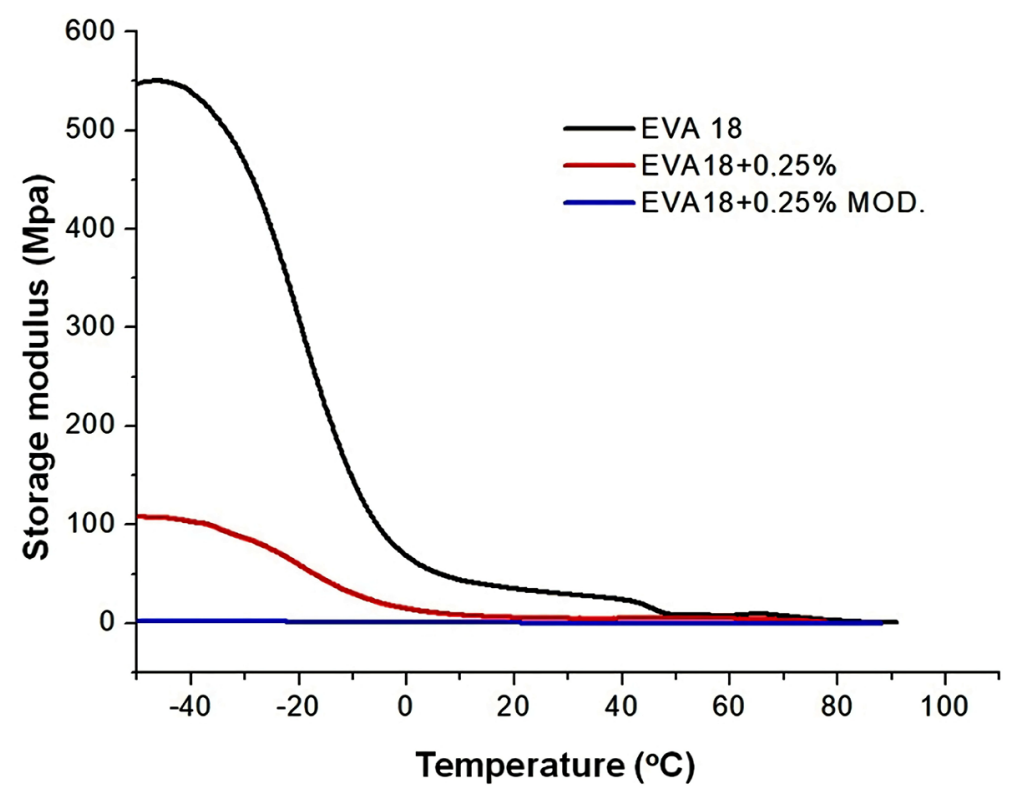

Figure 13. EVA/ZnOmod system storage module containing $0.25 \%$ of modified $\mathrm{ZnO}$.

systems containing modified nanoparticle, the addition of $0.25 \%$ modified $\mathrm{ZnO}$ further enhanced the decrease in storage modulus, suggesting that there was an increase in the nanoparticle-polymer interaction by improving the dispersion of the nanoparticle, hindering polymer-polymer. These data corroborate with the XRD analysis, which presented greater structural change with the addition of nanoparticle and absence of peaks related to pure oxide, indicating a better oxide dispersion.

The EVA/ZnOmod system containing $0.5 \%$ (Figure 14) behaved inversely, the modification of the nanoparticle promoted an increase of the storage modulus and greater response in phase. The presence of the modifier allowed the 


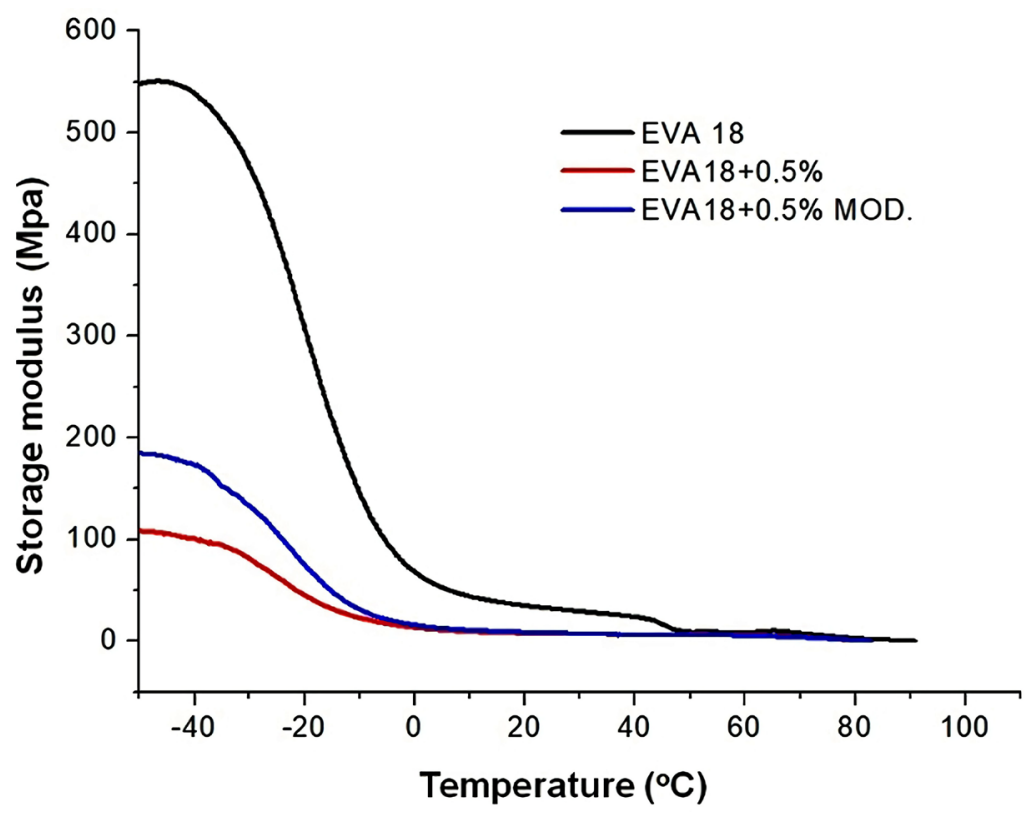

Figure 14. EVA/ZnOmod system storage module containing $0.5 \%$ of modified $\mathrm{ZnO}$.

addition of a higher concentration of zinc oxide, which increased rigidity of the system. These DMA results corroborate the XRD analysis, where the increase in the concentration of the modified nanoparticle led to interference in more organized regions.

The viscous EVA component decreases with the nanoparticle incorporation for all hybrid systems (Figure 15) when compared to the pristine copolymer. The behavior indicates change in the structural organization of the polymer by decreasing the free volume in the amorphous area of the matrix. The DMA results corroborate the XRD data, where there was a decrease in the contribution of the amorphous halo in the $\mathrm{EVA} / \mathrm{ZnO}$ systems, indicating the predominance of the oxide in the amorphous area.

The increase in $\mathrm{ZnO}$ ratios to $0.75 \%$ and $1 \%$ further intensifies the loss modulus diminish, indicating a decrease in free volume by $\mathrm{ZnO}$ dispersion in the matrix.

Regarding the pure copolymer, the systems containing modified nanoparticle presented variation of the loss modulus, where the EVA/ZnOmod system containing $0.25 \%$ (Figure 16) showed even greater decrease of the loss modulus. This suggests an increase in the interactions between polymer and nanoparticle, making even more difficult to dissipate energy in the internal medium of the polymer due to decrease of the free volume.

The system containing $0.5 \%$ modified nanoparticle also showed inverted behavior comparing to the $0.25 \% \mathrm{EVA} / \mathrm{ZnOmod}$ system (Figure 17), where the modification of the nanoparticle induces an increase of the loss modulus. This concentration allows the incorporation of more quantity of zinc oxide, as seen in the XRD analyzes, where the amorphous area of the XRD increases for the modified sample. 


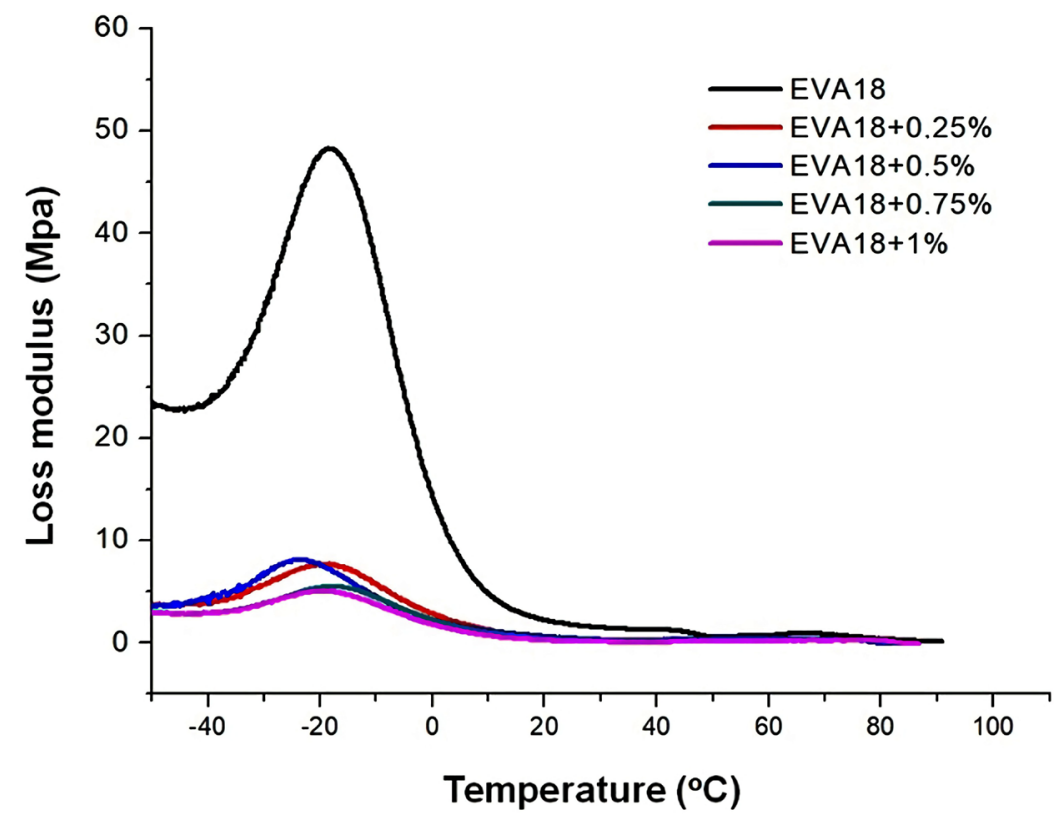

Figure 15. Loss module of EVA/ZnO systems in different $\mathrm{ZnO}$ proportions.

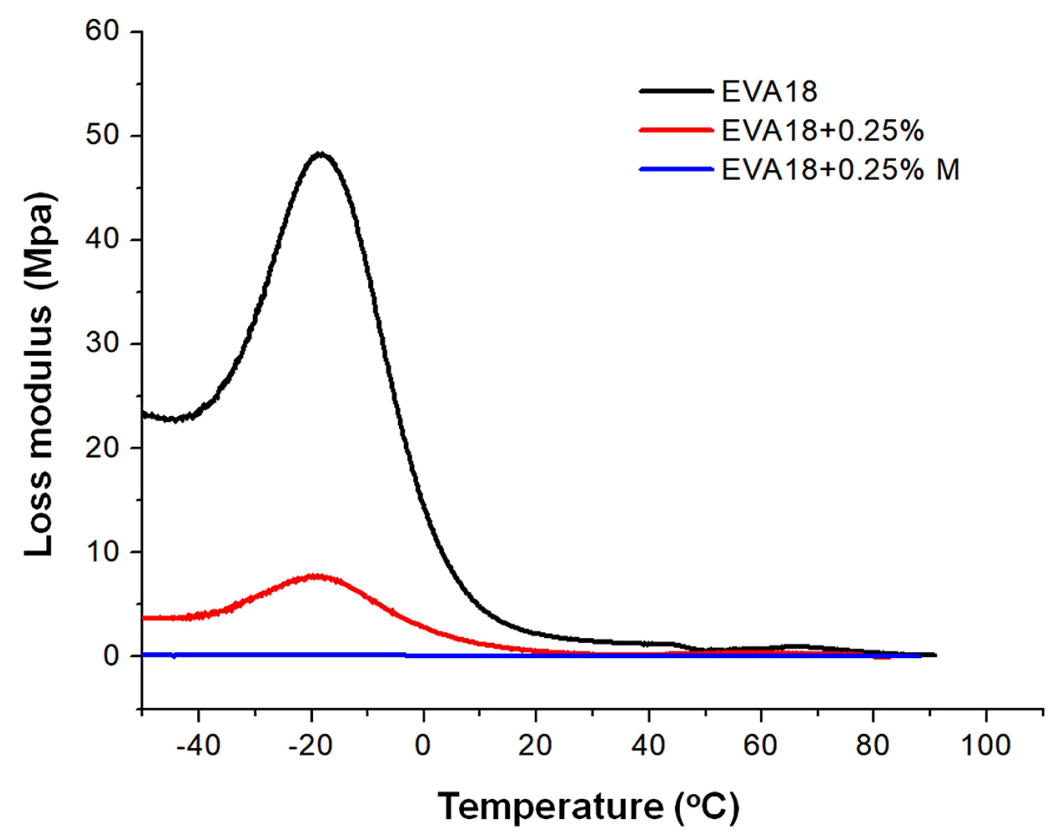

Figure 16. Loss module of the EVA/ZnOmod system containing $0.25 \%$ of modified $\mathrm{ZnO}$.

Tan $\delta$ analysis can give precise values of glass transition (Tg). The curves plotted from $\tan \delta$ relative to the temperature for EVA and EVA/ZnO nanocomposites are shown in Figure 18. The tan $\delta$ peak of pure EVA is about $-7^{\circ} \mathrm{C}$, which corresponds to the $\mathrm{Tg}$ of the polymer. For the EVA/ZnOmod nanocomposites, Tg temperatures did not change significantly, however, $\tan \delta$ values for systems containing unmodified nanoparticle are higher than pure EVA. This suggests that the addition of oxide limited the molecular mobility of the polymer chains, slightly increasing the stiffness of the system. 


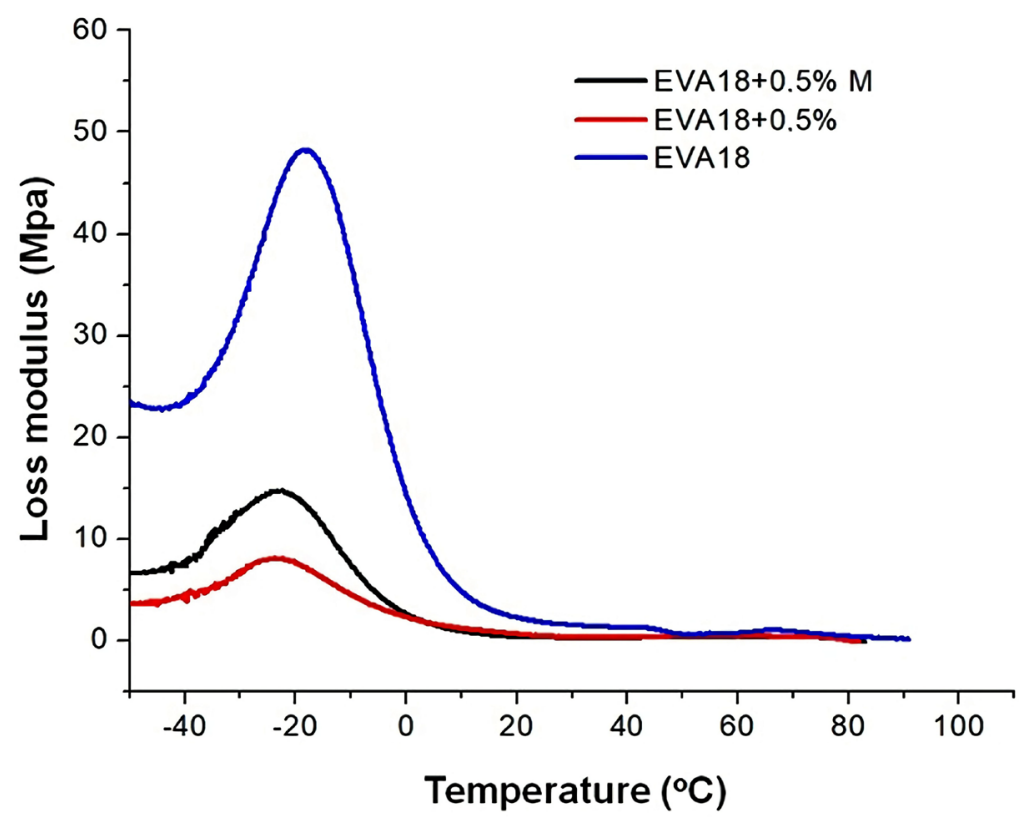

Figure 17. Loss module of the EVA/ZnOmod system containing $0.5 \%$ of modified $\mathrm{ZnO}$.

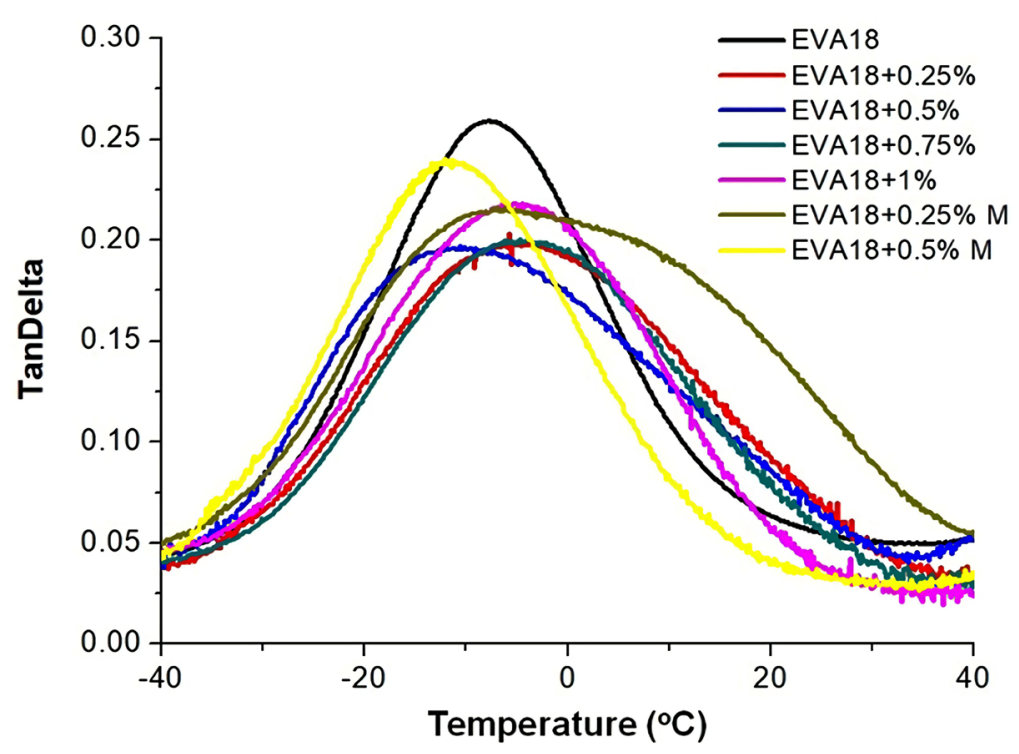

Figure 18. Tan of the EVA/ZnO systems in different proportions of $\mathrm{ZnO}$.

In the system containing $0.5 \%$ of modified nanoparticle there is a slight decrease of Tg value, indicating an increase in the molecular mobility of the system because of the nanoparticle ratio and the modification. This result confirms the $\mathrm{XRD}$ analysis, where this system presents an increase of the amorphous area, allowing the insertion of more oxide.

The intensity of the tan delta also allows evaluating the relationship between the storage and loss modules, indicating the variation of the damping as a function of the presence of the nanoparticle. It is possible to verify that the system containing $0.5 \%$ of modified nanoparticle presents higher damping than the other systems, which agrees with the increased contribution of the amorphous 
halo in the XRD analyzes. All systems containing nanoparticle would have lower impact strength than pure copolymer, indicating increased in the molecular rigidity with the presence of nanoparticle.

\subsection{Time Domain Nuclear Magnetic Resonance}

The samples were evaluated focusing the domain relaxation curves and the behavior of relaxation time. In relation to EVA, the domain curves of the EVA/ZnO systems (Figure 19) presented low mobility domains, in comparison to domains of high molecular mobility, indicating that the addition of oxide in the matrix favors the absorption of moisture. In addition, there was a slight broadening of domain curve containing $0.25 \%$. The presence of new domains and the subtle base broadening of the mobility curve indicate a change in the homogeneity of the material and corroborate the XRD analysis, which evidenced the structural change.

The addition of $0.5 \%$ of $\mathrm{ZnO}$ there is a behavior inversion, in what there is less dispersion of the nanoparticle and the for the systems containing $0.75 \%$ and $1 \%$ of zinc oxide present similar behavior to the pure polymer, this behavior indicates the saturation of the system due to a higher concentration of nanoparticle as already observed by other studies of nanocomposite systems [46] [47] [48]. This result agrees with the DMA analysis, where the proportion of $0.5 \%$ acted as a limit proportion, from which there is a behavior inversion of the EVA/ZnO systems in relation to the pure EVA.

The spin-lattice relaxation time measurements $\left(\mathrm{T}_{1,1} \mathrm{H}\right.$ and $\left.\mathrm{T}_{1,2} \mathrm{H}\right)$ are presented in Table 2.

Through the percentages of the mobile and rigid phases in $\mathrm{EVA} / \mathrm{ZnO}$ systems, it is possible to verify if the system stiffness increases. With $0.25 \%$ nanoparticle, the increase in stiffness confirms the decrease in the amorphous phase indicated

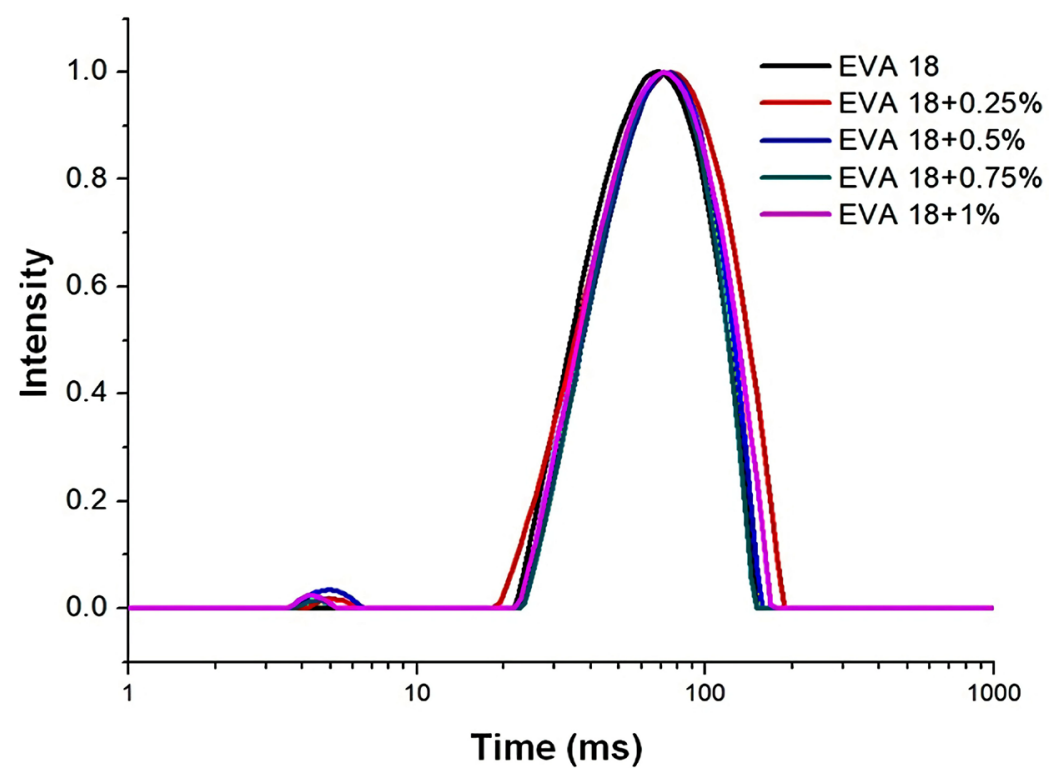

Figure 19. Domain Curves of EVA/ZnO systems in different proportions. 
Table 2. Values of relaxation data determined from two exponential $\left(\mathrm{T}_{1,1} \mathrm{H}\right.$ and $\left.\mathrm{T}_{1,2} \mathrm{H}\right)$.

\begin{tabular}{ccc}
\hline Samples & $\mathrm{T}_{1,1} \mathrm{H}(\%) \pm 2 \%$ & $\mathrm{~T}_{1,2} \mathrm{H}(\%) \pm 2 \%$ \\
\hline EVA18 0.25\% ZnO & 12 & 77 \\
EVA18 0.25\% ZnO Mod & 20 & 76 \\
EVA18 0.50\% ZnO & 16 & 76 \\
EVA18 0.50\% ZnO Mod & 22 & 74 \\
\hline
\end{tabular}

by XRD. In $0.5 \%$ there is a slight decrease in the rigid fraction, corroborating the XRD which showed an increase in the amorphous halo contribution. At higher nanoparticle percentages, such as $0.75 \%$ and $1 \%$, the increase in hard $\mathrm{T}_{1}$ still occurs. Increasing the amount of oxide in the systems decreased the contribution of mobile $\mathrm{T}_{1}$, indicating the existence of $\mathrm{ZnO}$ in the amorphous area of the polymer.

The spin-lattice relaxation data of the systems containing modified nanoparticle, presented differences in relation to the EVA/ZnO systems with $0.25 \%$ and $0.5 \%$. In both systems, the nanoparticle modification led to $\mathrm{T}_{1.1} \mathrm{H}$ increase, elucidating decrease of the molecular mobility of the polymer along with the increase of the polymer-nanoparticle interaction and indicating greater dispersion of the oxide in the amorphous area of the material [47] [48] [49], where there is no variation of the percentage of $\mathrm{T}_{1,2} \mathrm{H}$ with nanoparticle modification. These data corroborate the results of DMA, where the analysis indicated that the modification induced an increase in the polymer-nanoparticle interactions. The DRX also rectifies this behavior, where the $0.25 \%$ modification possibly caused interference in more amorphous regions.

Finally, for the concentration of nanoparticle in the systems, it is possible to verify that increasing zinc oxide proportion in nanocomposites affected the structural organization of the system; the $0.5 \% \mathrm{ZnO}$ proportion was observed to be a borderline for nanoparticle incorporation, with changes in the structural characteristics of the system. The modification indicated higher nanoparticle-polymer interaction, with higher contribution of the amorphous halo in the crystallinity of the polymer matrix, change of the system mobility and variation of the dynamic mechanical characteristics.

\section{Conclusion}

From the results obtained, it was possible to infer that the presence of zinc oxide in the EVA matrix can alter the structural organization of the polymer, resulting in different properties when compared to the pure polymer. The concentration of $0.25 \%$ turned out to perform better among EVA/ZnO systems, where the amount of nanoparticle inserted in the matrix was enough to change the crystallinity and mechanical properties of the material, with subtle increase of thermal stability.

\section{Conflicts of Interest}

The authors declare no conflicts of interest regarding the publication of this paper. 


\section{References}

[1] Omrani, A., Simon, B.L.C. and Rostami, A.A. (2009) The Effects of Alumina Nanoparticle on the Properties of an Epoxy Resin System Materials. Materials Chemistry and Physics, 114, 145-150. https://doi.org/10.1016/j.matchemphys.2008.08.090

[2] Emamifar, A. (2011) Applications of Antimicrobial Polymer Nanocomposites in Food Packaging. In: Hashim, A., Ed., Advances in Nanocomposite Technology, IntechOpen, London. https://doi.org/10.5772/18343

[3] Biji, K.B., Ravishankar, C.N. and Mohan, C.O. (2015) Smart Packaging Systems for Food Applications: A Review. Journal of Food Science and Technology, 52, 6125-6135. https://doi.org/10.1007/s13197-015-1766-7

[4] Hotchkiss, J.H. and Appendini, P. (2002) Review of Antimicrobial Food Packaging. Innovative Food Science and Emerging Technologies, 3, 113-126. https://doi.org/10.1016/S1466-8564(02)00012-7

[5] Espitia, P.J.P., Soaresa, N.F.F., Teófilo, R.F., Coimbra, J.S.R., Vitora, D.M., Batista, R.A., Ferreira, S.O., Andrade, N.J. and Medeiros, E.A.A. (2013) Physical-Mechanical and Antimicrobial Properties of Nanocomposite Films with Pediocin and $\mathrm{ZnO}$ Nanoparticles. Carbohydrate Polymers, 94, 199-208. https://doi.org/10.1016/j.carbpol.2013.01.003

[6] Bastarrachea, L., Dhawan, S. and Sablani, S.S. (2011) Engineering Properties of Polymeric-Based Antimicrobial Films for Food Packaging: A Review. Food Engineering Review, 3, 79-93. https://doi.org/10.1007/s12393-011-9034-8

[7] Merah, A., Abidi, A., Merad, H., Gherraf, N., Iezid, M. and Djahoudi, A. (2019) Comparative Study of the Bacteriological Activity of Zinc Oxide and Copper Oxide Nanoparticles. Acta Scientiarum Naturalium, 6, 63-72.

https://doi.org/10.2478/asn-2019-0009

[8] Jones, N., Ray, B., Ranjit, K.T. and Manna, A.C. (2008) Antibacterial Activity of $\mathrm{ZnO}$ Nanoparticle Suspensions on a Broad Spectrum of Microorganisms. FEMS Microbiology Letters, 279, 71-76. https://doi.org/10.1111/j.1574-6968.2007.01012.x

[9] Akbar, A., Sadiq, M.B., Ali, I., Muhammad, N., Rehman, Z., Khan, M.N., Muhammad, J., Khan, S.A., Rehman, F.U. and Anal, A.K. (2019) Synthesis and Antimicrobial Activity of Zinc Oxide Nanoparticles against Foodborne Pathogens Salmonella typhimurium and Staphylococcus aureus. Biocatalysis and Agricultural Biotechnology, 17, 36-42. https://doi.org/10.1016/j.bcab.2018.11.005

[10] Seil, J.T. and Webster, T.J. (2012) Antimicrobial Applications of Nanotechnology: Methods and Literature. International Journal of Nanomedicine, 7, 2767-2781. https://doi.org/10.2147/IJN.S24805

[11] Emami-Karvani, Z. and Chehrazi, P. (2011) Antibacterial Activity of ZnO Nanoparticle on Gram-Positive and Gram-Negative Bacteria. African Journal of Microbiology Research, 5, 1368-1373. https://doi.org/10.5897/AJMR10.159

[12] Dumbrava, A., Berger, D., Matei, C., Prodan, G., Aonofriesei, F., Radu, M.D. and Moscalu, F. (2019) New Composite Nanomaterials with Antimicrobial and Photocatalytic Properties Based on Silver and Zinc Oxide. Journal of Inorganic and Organometallic Polymers and Materials, 29, 2072-2082.

https://doi.org/10.1007/s10904-019-01166-4

[13] Raghupathi, K.R., Koodali, R.T. and Manna, A.C. (2011) Size-Dependent Bacterial Growth Inhibition and Mechanism of Antibacterial Activity of Zinc Oxide Nanoparticles. Langmuir, 27, 4020-4028. https://doi.org/10.1021/la104825u

[14] Adams, L.K., Lyon, D.Y. and Alvarez, P.J.J. (2006) Comparative Eco-Toxicity of 
Nanoscale $\mathrm{TiO}_{2}, \mathrm{SiO}_{2}$, and $\mathrm{ZnO}$ Water Suspensions. Water Research, 40, 3527-3532. https://doi.org/10.1016/j.watres.2006.08.004

[15] Bhadra, P., Mitra, M.K., Das, G.C., Dey, R. and Mukherjee, S. (2011) Interaction of Chitosan Capped ZnO Nanorods with Escherichia coli. Materials Science and Engineering C, 31, 929-937. https://doi.org/10.1016/j.msec.2011.02.015

[16] Brayner, R., Ferrari-Iliou, R., Brivois, N., Djediat, S., Benedetti, M.F. and Fiévet, F. (2006) Toxicological Impact Studies Based on Escherichia coli Bacteria in Ultrafine ZnO Nanoparticles Colloidal Medium. Nano Letters, 6, 866-870. https://doi.org/10.1021/nl052326h

[17] Gordon, T., Perlstein, B., Houbara, O., Felner, I., Banin, E. and Margel, S. (2011) Synthesis and Characterization of Zinc/Iron Oxide Composite Nanoparticles and Their Antibacterial Properties. Colloids and Surfaces A, 374, 1-8. https://doi.org/10.1016/j.colsurfa.2010.10.015

[18] Hirota, K., Sugimoto, M., Kato, M., Tsukagoshi, K., Tanigawa, T. and Sugimoto, H. (2010) Preparation of Zinc Oxide Ceramics with a Sustainable Antibacterial Activity under Dark Conditions. Ceramics International, 36, 497-506.

https://doi.org/10.1016/j.ceramint.2009.09.026

[19] da Silva, B.L., Abuçafy, M.P., Manaia, E.B., Junior, J.A.O., Chiari-Andréo, B.G., Pietro, R.C.R. and Chiavacci, L.A. (2019) Relationship between Structure and Antimicrobial Activity of Zinc Oxide Nanoparticles: An Overview. International Journal of Nanomedicine, 14, 9395-9410. https://doi.org/10.2147/IJN.S216204

[20] Kasemets, K., Ivask, A., Dubourguier, H.C. and Kahru, A. (2009) Toxicity of Nanoparticles of $\mathrm{ZnO}, \mathrm{CuO}$ and $\mathrm{TiO}_{2}$ to Yeast Saccharomyces cerevisiae. Toxicology in Vitro, 23, 1116-1122. https://doi.org/10.1016/j.tiv.2009.05.015

[21] He, L., Liu, Y., Mustapha, A. and Lin, M. (2011) Antifungal Activity of Zinc Oxide Nanoparticles against Botrytis cinerea and Penicillium expansum. Microbiological Research, 166, 207-215. https://doi.org/10.1016/j.micres.2010.03.003

[22] Zhu, X., Pathakoti, K. and Huey-Min, H. (2019) Green Synthesis of Titanium Dioxide and Zinc Oxide Nanoparticles and Their Usage for Antimicrobial Applications and Environmental Remediation. In: Green Synthesis, Characterization and Applications of Nanoparticles, Elsevier, Amsterdam, 223-263. https://doi.org/10.1016/B978-0-08-102579-6.00010-1

[23] Premanathan, M., Karthikeyan, K., Jeyasubramanian, K. and Manivannan, G. (2011) Selective Toxicity of ZnO Nanoparticles toward Grampositive Bacteria and Cancer Cells by Apoptosis through Lipid Peroxidation. Nanomedicine, 7, 184-192. https://doi.org/10.1016/j.nano.2010.10.001

[24] Reddy, K.M., Feris, K., Bell, J., Wingett, D.G., Hanley, C. and Punnoose, A. (2007) Selective Toxicity of Zinc Oxide Nanoparticles to Prokaryotic and Eukaryotic Systems. Applied Physics Letters, 90, 2139021-2139023.

https://doi.org/10.1063/1.2742324

[25] Sawai, J. (2003) Quantitative Evaluation of Antibacterial Activities of Metallic Oxide Powders ( $\mathrm{ZnO}, \mathrm{MgO}$ and $\mathrm{CaO}$ ) by Conductimetric Assay. Journal of Microbiological Methods, 54, 177-182. https://doi.org/10.1016/S0167-7012(03)00037-X

[26] Zhang, L., Ding, Y., Povey, M. and York, D. (2008) ZnO Nanofluids-A Potential Antibacterial Agent. Progress in Natural Science, 18, 939-944. https://doi.org/10.1016/j.pnsc.2008.01.026

[27] Zhang, L., Jiang, Y., Ding, Y., Povey, M. and York, D. (2007) Investigation into the Antibacterial Behaviour of Suspensions of $\mathrm{ZnO}$ Nanoparticles (ZnO Nanofluids). Journal of Nanoparticle Research, 9, 479-489. 
https://doi.org/10.1007/s11051-006-9150-1

[28] Buzea, C., Pacheco, I.I. and Robbie, K. (2007) Nanomaterials and Nanoparticles: Sources and Toxicity. Biointerphases, 2, 17-71. https://doi.org/10.1116/1.2815690

[29] Jamroz, N.U. (2003) Determination of Vinyl Acetate (VA) Content of Ethylene-Vinyl Acetate (EVA) Copolymers in Thick Films by Infrared Spectroscopy. Journal of the Chemical Society of Pakistan, 25, 84-87.

[30] Mousavi, S.A., Gholizadeh, M., Sedghi, S., Pourafshari-Chemar, M., Bernala, M. and Soltani, A. (2010) Effects of Preparation Conditions on the Morphology and Gas Permeation Properties of Polyethylene (PE) and Ethylene Vinyl Acetate (EVA) Films. Chemical Engineering Research and Design, 88, 1593-1598.

https://doi.org/10.1016/j.cherd.2010.03.013

[31] Khairy, M., Amin, N.H. and Kamal, R. (2017) Optical and Kinetics of Thermal Decomposition of PMMA/ZnO Nanocomposites. Journal of Thermal Analysis and Calorimetry, 128, 1811-1824. https://doi.org/10.1007/s10973-016-6062-x

[32] Bumbudsanpharoke, N., Choi, J., Park, H.J. and Ko, S. (2019) Zinc Migration and Its Effect on the Functionality of a Low Density Polyethylene-ZnO Nanocomposite Film. Food Packaging and Shelf Life, 20, 1-8. https://doi.org/10.1016/j.fpsl.2019.100301

[33] Xiong, G., Pal, U., Serrano, J.G., Ucer, K.B. and Williams, R.T. (2006) Photoluminescence and FTIR Study of $\mathrm{ZnO}$ Nanoparticles: The Impurity and Defect Perspective. Physica Status Solidi, 3, 3577-3581. https://doi.org/10.1002/pssc.200672164

[34] Zhang, S.P. and Song, H.O. (2012) Supramolecular Graphene Oxide-Alkylamine Hybrid Materials: Variation of Dispersibility and Improvement of Thermal Stability. New Journal of Chemistry, 36, 1733-1738. https://doi.org/10.1039/c2nj40214a

[35] Monteiro, M.S.S.B. and Tavares, M.I.B. (2018) The Development and Characterization of Polycaprolactone and Titanium Dioxide Hybrids. Advances in Nanoparticles, 7, 11-27. https://doi.org/10.4236/anp.2018.71002

[36] Silva, M.B.R., Junior, A.W.M., Neto, R.P.C. and Tavares, M.I.B. (2016) Evaluation of Intermolecular Interactions in the $\mathrm{PHB} / \mathrm{ZnO}$ Nanostructured Materials. Journal of Nanoscience and Nanotechnology, 16, 7606-7610. https://doi.org/10.1166/jnn.2016.11760

[37] Giurginca, M., Popa, L. and Zaharescu, T. (2003) Thermo-Oxidative Degradation and Radio-Processing of Ethylene Vinyl Acetate Elastomers. Polymer Degradation and Stability, 82, 463-466. https://doi.org/10.1016/S0141-3910(03)00200-3

[38] Sefadi, J.S. and Luyt, A.S. (2012) Morphology and Properties of EVA/Empty Fruit Bunch Composites. Journal of Thermoplastic Composite Materials, 25, 895-914. https://doi.org/10.1177/0892705711421806

[39] Zubkiewicz, A., Szymczyk, A., Paszkiewicz, S., Jędrzejewski, R., Piesowicz, E. and Siemiński, J. (2020) Ethylene Vinyl Acetate Copolymer/Halloysite Nanotubes Nanocomposites with Enhanced Mechanical and Thermal Properties. Journal of Applied Polymer Science, 1-12. https://doi.org/10.1002/app.49135

[40] Corrêa, A.C., Teodoro, K.B.R., Simão, J.A., Claro, P.I.C., Teixeira, E.M., Mattoso, L.H.C. and Marconcini, J.M. (2020) Cellulose Nanocrystals from Curaua Fibers and Poly[ethylene-co-(vinyl acetate)] Nanocomposites: Effect of Drying Process of CNCs on Thermal and Mechanical Properties. Polymer Composites, 1-13. https://doi.org/10.1002/pc.25493

[41] Wang, K. and Deng, Q. (2019) The Thermal and Mechanical Properties of Poly(ethylene-co-vinyl acetate) Random Copolymers (PEVA) and Its Covalently Crosslinked Analogues (cPEVA). Polymer, 11, 1-18. 
https://doi.org/10.3390/polym11061055

[42] Cottaz, A., Bouarab, L., De Clercq, J., Oulahal, N., Degraeve, P. and Joly, C. (2019) Potential of Incorporation of Antimicrobial Plant Phenolics into Polyolefin-Based Food Contact Materials to Produce Active Packaging by Melt-Blending: Proof of Concept with Isobutyl-4-Hydroxybenzoate. Frontiers in Chemistry, 7, 148. https://doi.org/10.3389/fchem.2019.00148

[43] Ahmad, J., Deshmukh, K., Habib, M. and Hägg, M.B. (2014) Influence of $\mathrm{TiO}_{2} \mathrm{Na}$ noparticles on the Morphological, Thermal and Solution Properties of PVA/ $\mathrm{TiO}_{2}$ Nanocomposite Membranes. Arabian Journal for Science and Engineering, 39, 6805-6814. https://doi.org/10.1007/s13369-014-1287-0

[44] Heidarbeigi, J., Borghei, A.M. and Afshari, H. (2019) The Mechanical and Thermal Properties of PE/CNC Nanocomposite. International Journal of Nano Dimension, 10, 209-216.

[45] Rapp, G., Tireau, J., Bussiere, P.O., Chenal, J.M., Rousset, F., Chazeau, L., Gardette, J.L. and Therias, S. (2019) Influence of the Physical State of a Polymer Blend on Thermal Ageing. Polymer Degradation and Stability, 163, 161-173. https://doi.org/10.1016/j.polymdegradstab.2019.03.006

[46] Passos, A.A., Tavares, M.I.B., Neto, R.C.P. and Ferreira, A.G. (2012) The Use of Solid State NMR to Evaluate EVA/Silica Films. Journal of Nano Research, 18, 219-226. https://doi.org/10.4028/www.scientific.net/JNanoR.18-19.219

[47] Iulianelli, G.C.V., Sebastião, P.J.O., Tavares, M.I.B. and dos Santos, F.A. (2015) Influence of Organoclay Structure on Nanostructured Materials Based on EVA. Materials Sciences and Applications, 6, 860-868. https://doi.org/10.4236/msa.2015.610088

[48] Mota, R.C.D.A.G., Silva, E.O. and Menezes, L.R. (2019) Coating of 3D Printed Scaffolds with PVA-Based Metallic Oxides Nanocomposites for Bone Tissue Regeneration. Sciences (IRJPMS), 2, 55-62.

[49] Besghini, D., Mauri, M. and Simonutti, R. (2019) Time Domain NMR in Polymer Science: From the Laboratory to the Industry. Applied Sciences, 9, 1801. https://doi.org/10.3390/app9091801 